varnish. Part three (hillslopes) covers rock slopes, rock-mantled slopes and badlands, and includes a brief but useful chapter by C. Francis on vegetation.

The two chapters in part four (rivers) cover catchment and channel hydrology, and channel processes and forms. Part six introduces the hydrographic and geomorphic patterns of hemi-arid lake basins, a subject typically played down or even ignored in most books on desert geomorphology. Part seven (aeolian surfaces) covers aeolian sediment transport, dune morphology and dynamics, and landforms resulting from aeolian erosion. The last seven chapters, grouped under the title "Climatic Change", bring together many of the themes treated earlier, but in the important context of the role of time and climate variation in the development of today's desert geomorphology, after the operation of the extreme and rapid climate changes of the later Cenozoic era and the Quaternary period.

In addition to the scientific challenges, the sensitivity and human importance of desert environments, and especially the vexed issue of desertification, make it unsurprising that books on desert geomorphology and processes are published so often. Happily, Geomorphology of Desert Environments is a worthy and desirable newcomer, amplifying and in many respects complementing Desert Geomorphology by R. U. Cooke, A. Warren and A. S. Goudie (UCL Press, 1993; for a review see Nature 363, 313; 1993).

The new work's emphasis on North America is not objectionable and there is little to disappoint. Generally, the chapters are comprehensive and thoroughly researched, with lengthy bibliographies, and several contain original material. The insights into the origins of badlands and hillslopes that A. D. Howard has gained using simulation models fully justify the application of the technique and suggest that its use would be beneficial in other geomorphological realms. D. R. Currey gives an incisive hydrographic and geomorphological analysis of hemi-arid lake basins and their sediment fills perhaps limitations of space prevented him from further illustrating his case with field photographs and maps.

The book is generally well illustrated, but the reader may find that some of the photographs are too small and their contrast excessive. Some of the line drawings are fuzzy and poorly lettered.

J. R. L. Allen is in the Postgraduate Research Institute for Sedimentology, University of Reading, Whiteknights, PO BOx 227, Reading RG6 $2 A B$, UK.

- Geomorphology in the Tropics: A Study of Weathering and Denudation in Low Latitudes by Michael F. Thomas has just been published by Wiley at $£ 85$.

\section{From DNA to databases}

Chris Rawlings

Guide to Human Genome Computing. Edited by Martin J. Bishop. Academic Press: 1994. Pp. 350. £25, \$39.95 (pbk).

Computer Analysis of Sequence Data. Two volumes. Edited by Annette $M$. Griffin and Hugh G. Griffin. Humana: 1994. Pp. 372 and 433. \$59.95 each.

MosT molecular biologists and geneticists today rely on computer software for collecting data, retrieving sequence and genetic information from databases, or interpreting sequence or recombination frequency data. But programs remain complex and difficult to master. The mismatch between the software skills and the scientific needs of molecular biologists not only reflects the pace of new technological development; it also reveals a weakness in education and training. The management and analysis of data could well prove to be a bottleneck in genome projects.

So we should welcome these two publications, which aim to make software more accessible and scientists more aware. Although ostensibly covering the same topic areas, the books adopt different approaches. Guide to Human Genome Computing is more conventional, each chapter providing an introduction to the principles of software together with guidance on the use of programs, and liberally illustrated with examples and figures. The coverage is broad and aimed at the molecular geneticist involved in a variety of research areas from genetic linkage analysis, physical mapping data management, sequence assembly, sequence comparison, inferring biochemical function from sequence data and the use of comparative genetic maps. Many authors go to great lengths to compare a range of different software tools, showing that there is generally no best solution to complex problems such as genetic linkage and sequence comparison - different programs give different answers depending on how they are used.

Much of the material in this book arose from the training courses run at the UK Medical Research Council Human Genome Project Resource Centre. Occasionally, some parochialism shows through. But overall the book will appeal to a wide community of genome scientists.

Computer Analysis of Sequence Data comes in two volumes and focuses on programs rather than problems. The main sections cover the Genetics Computer Group (13 chapters) and the Staden (13 chapters) software suites, software for IBM-compatible personal computers (in- cluding the $\mathrm{PC} / \mathrm{Gene}$ programs (6 chapters) and also, rather surprisingly, the now obsolete MicroGenie software (5 chapters)) and programs for the Apple Macintosh (including MacVector (5 chapters) and DNA Strider). Other chapters deal with individual programs, and include a useful overview of methods for multiple protein sequence alignment while introducing some of the problems of phylogenetic inference.

The programs are presented in a practical step-by-step fashion, and the notes at the end of most chapters provide useful hints and warnings. But despite some excellent contributions, the value of the book as a whole is marred by a lack of illustrations and by repetition resulting from the rigid "Materials-MethodsResults" structure. Also, five chapters appear in both volumes (presumably some people will buy only one or the other). Although the choice of repeated material is for the most part reasonable (covering sequence comparison with the FASTA program, the submission of sequence data to the database curators and the conversion of data to different data formats), the duplicated chapter about Internet is somewhat dated and parochial. There are other signs that the book was conceived several years ago: for example, it is surprising that there is no mention of the BLAST program for rapid sequence database searching. Finally, the rather inadequate index contains no cross-references between the two volumes.

Nevertheless, the detailed program recipes in Computer Analysis of Sequence Data will provide a useful adjunct to user manuals.

Chris Rawlings is in the Biomedical Informatics Unit, Imperial Cancer Research Fund, PO Box 123, Lincoln's Inn Fields, London WC2A 3PX, UK.

\section{New in paperback Collins Dictionary of Astronomy edited by Valerie Illingworth. A new edition, revised and updated, of the Macmillan Dictionary of Astronomy, which was first published in 1979 and revised for a second edition in 1985. A team of 24 professional astronomers contribute more than 3,500 entries. HarperCollins, £8.99.}

In the Beginning: The Birth of the Living Universe by John Gribbin. A guide for the lay person to ideas about the connection between cosmology and evolution. Penguin, $£ 6.99$.

Defenders of the Text: The Traditions of Scholarship in an Age of Science, 1450 $-\mathbf{1 8 0 0}$ by Anthony Grafton. A series of scholarly but lively essays on the relation between humanism and science, focusing on Poliziano,

Scaliger, Kepler and Wolf. Harvard University Press, $\$ 20.25$, $£ 13.50$. 